\title{
Cases of assault attending a childrens accident and emergency department: an epidemiological study
}

\author{
R. S. MOORE \& W. J. ROBSON
}

Accident and Emergency Department, Royal Liverpool Childrens Hospital, Alder Hey, Liverpool

\section{INTRODUCTION}

Recent studies have drawn attention to victims of assault attending A\&E departments. These have been concerned mainly with adult cases and have shown a strong association with alcohol ingestion (Driscoll et al., 1988). A paediatric accident unit regularly sees children who have been assaulted, but alcohol consumption is rarely involved. A prospective study was undertaken to describe the character of assaults leading to attendance at the A\&E Department of the Royal Liverpool Childrens Hospital (Alder Hey) over a period of 4 months.

\section{METHODS}

All children attending the A\&E Unit of the Royal Liverpool Childrens Hospital (Alder Hey) between 25th October 1988 and 27th February 1989 who complained of being assaulted were included in the study. The term assault described any act against the person made wilfully by another, without the consent of the former. Information was collected by questionnaire on the following features: the age of the patient; the age of the assailant; the relationship (if any) with the victim; the time and day of attendance; the motive for the assault; the site of the assault; the treatment of the injuries; the need for any investigations and the use of weapons.

\section{RESULTS}

During the period of this study Alder Hey A\&E Department had 13951 new attendances. One hundred and ten children were the alleged victims of assaults. 
Three of these children were admitted. There were 80 boys and 30 girls. The age distribution is shown in Table 1. Teenage males formed the largest group.

Table 2 shows the ages of the assailants as estimated by the victims or as known to the childrens parents. It can be seen that the majority of assaults on very young children were by adults. On the contrary, most assaults on teenagers were by their immediate peers $(P=<0.0001)$

Over half of the children were able to identify their assailants, most being acquaintances from school or the neighbourhood, but many did not know their assailants (Table 3). A small group of assailants came from within the home environment. Most of these cases were related to child abuse. There was no reported case of injury by a sibling.

Table 4 shows the site where these assaults were committed according to the age of the victims. The term 'public places' refers to public transport, leisure centres and youth clubs etc. Most of the pre-school incidents occurred in the home, whereas in older children, more assaults occurred in the streets.

Table 5 describes the perceived motivation behind these cases. In the majority, no motive was apparent. Chastisement of a child sometimes went as far as physical injury. These instances could perhaps have been included in the abuse groups. Abuse and chastisement was significantly more common in children under the age of 12 years $(P=<0.0001)$. In twelve instances a weapon was used, e.g. an airgun, stones, sticks of various kinds, a glass bottle, a belt.

The majority of cases attended on weekdays and usually after midday, similar to the distribution for total attendances during the period of the study (see Figs $b$ \& 2). Table 6 shows the patterns of injury sustained in these assault. Injuries to the head and neck, either alone or in association with other injuries, were by fap?

Table 1. Chart to show the age distribution of victims.

\begin{tabular}{lrrrr}
\hline & \multicolumn{4}{c}{ Age (years) } \\
& $0-4$ & $5-11$ & $12-16$ & Total \\
\hline Male & 5 & 20 & 55 & 80 \\
Female & 5 & 9 & 16 & 30 \\
Total & 10 & 29 & 71 & 110 \\
\hline
\end{tabular}

Table 2. To show the relationship between age of assailant and age of victim (Chi-square $=35.15$, d.f. $=6, P=<0.0001$ ).

\begin{tabular}{lcccc}
\hline \multicolumn{5}{c}{ Age of assailant } \\
Victims & $0-10$ & $11-18$ & $19-40$ & $40+$ \\
\hline $0-4$ & 1 & 1 & 8 & 0 \\
$5-11$ & 5 & 11 & 12 & 1 \\
$12-16$ & 0 & 56 & 13 & 2 \\
Total & 6 & 68 & 33 & 3 \\
\hline
\end{tabular}


Table 3. To show the relationship between the assailant and the victim.

\begin{tabular}{lcccccc}
\hline \multicolumn{7}{c}{ Relationship to the victim } \\
Age & Nil & Acquaintance & Parent & Step-parent & Sib & Other \\
\hline $0-4$ & 2 & 1 & 3 & 1 & 0 & 3 \\
$5-11$ & 12 & 8 & 6 & 1 & 0 & 2 \\
$12-16$ & 26 & 39 & 3 & 2 & 0 & 1 \\
Total & 40 & 48 & 12 & 4 & 0 & 6 \\
\hline
\end{tabular}

Table 4. To show the site of assaults in relation to the age of the victim.

\begin{tabular}{lcccc}
\hline & \multicolumn{4}{c}{ Site of assault } \\
Age & Street & School & Public place & Home \\
\hline $0-4$ & 1 & 1 & 0 & 8 \\
$5-11$ & 7 & 6 & 7 & 9 \\
$12-16$ & 36 & 17 & 8 & 10 \\
Total & 44 & 24 & 15 & 27 \\
\hline
\end{tabular}

Table 5. To show the motive for assault related to age group (Chi-square $=38.49$, d.f. $=8$, $P=<0.0001$ ).

\begin{tabular}{lccccc}
\hline Age & Theft & Feud & $\begin{array}{c}\text { Motive for assault } \\
\text { Abuse }\end{array}$ & Chastisement & Unknown \\
\hline $0-4$ & 0 & 0 & 6 & 1 & 3 \\
$5-11$ & 0 & 6 & 7 & 4 & 12 \\
$12-16$ & 3 & 34 & 2 & 2 & 30 \\
Total & 3 & 40 & 15 & 7 & 45 \\
\hline
\end{tabular}

Table 6. To show the distribution of injuries; 12 cases had no injury.

\begin{tabular}{lcccccc}
\hline & Head/neck & Chest & $\begin{array}{l}\text { Site of injuries } \\
\text { Abdomen }\end{array}$ & Perineum & Upper limb & Lower limb \\
\hline $\begin{array}{l}\text { Alone } \\
\begin{array}{l}\text { With } \\
\text { head/ } \\
\text { neck }\end{array}\end{array}$ & 63 & 0 & 2 & 1 & 6 & 9 \\
\hline
\end{tabular}

the most common. Most of the injuries were minor and in 12 individuals there was no visible evidence of injury. Sixty-six cases required no investigation while the remaining 44 underwent radiological assessment. Two of these children also needed coagulation studies because of severe bruising. 


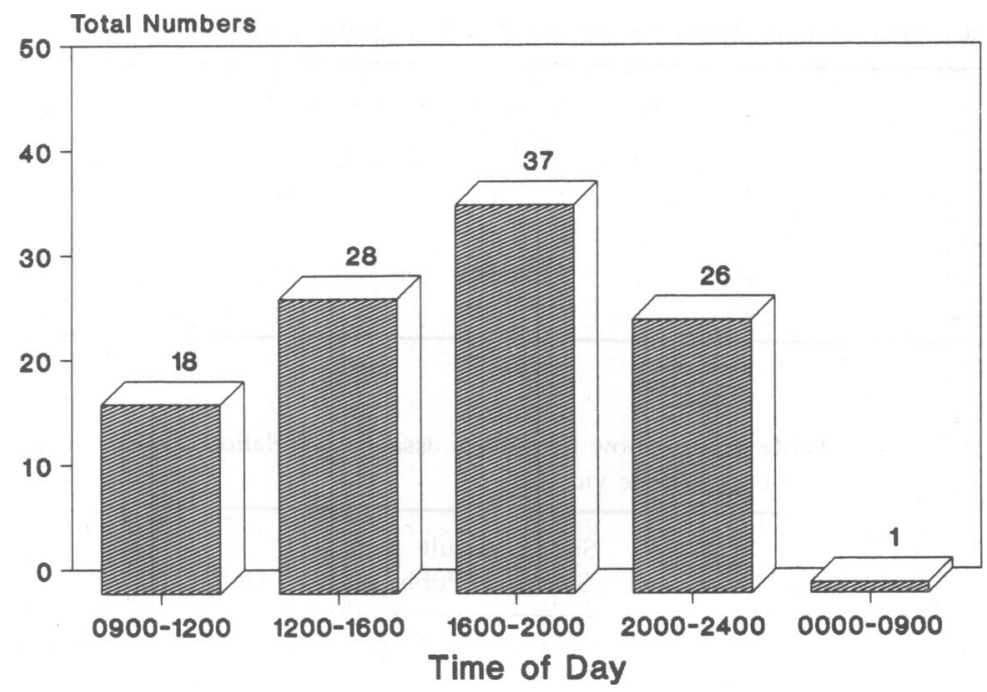

Fig. 1. Bar chart to indicate frequency of attendance by time of day.

\section{DISCUSSION}

One hundred and ten cases of assault were seen at Alder Hey during this study forming less than $1 \%$ of new cases. This represents only part of the problem in Liverpool as children are also seen at two other A\&E units in the city. Most of the

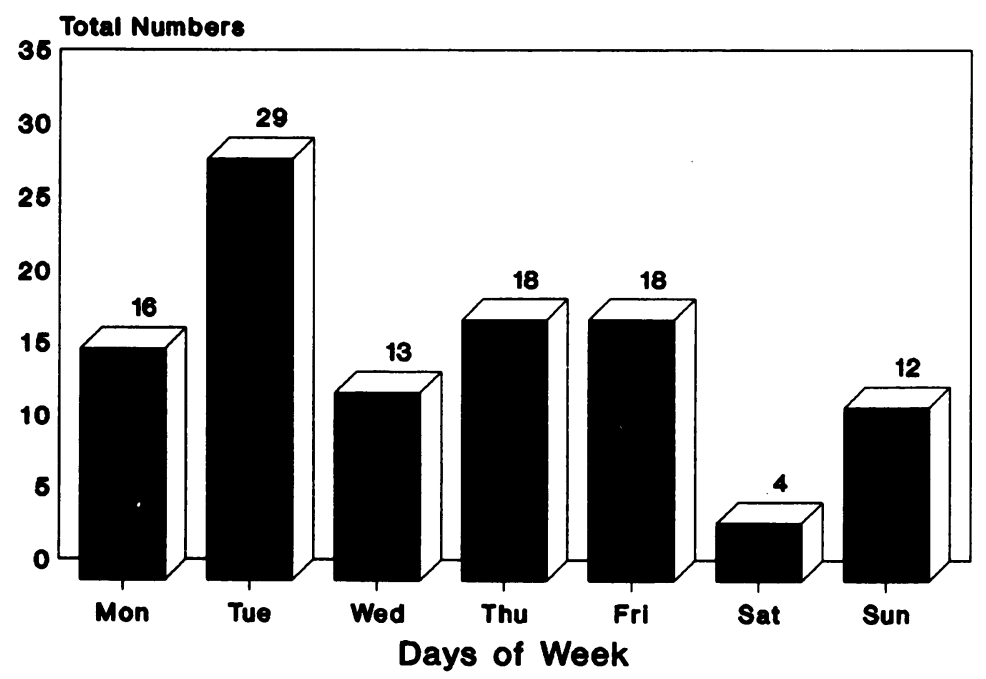

Fig. 2. Bar chart to indicate frequency of attendance by day of week. 
incidents occurred in the street away from adult supervision but in the very young more assaults occurred within the home and were instances of abuse. Most child abuse takes place in the domestic environment - preschool children spend much of their time at home. Proven cases of abuse made up $13.6 \%$ of the cases in this study and was significantly more common in children aged 11 years or less. In 1987 the Merseyside Police recorded 906 acts of violence against children up to the age of 16 years (about $18 \%$ of all violent offences). While the level of physical assault has been increasing at about $4 \%$ per annum (in line with national trends), the frequency of sexual abuse/assault has been rising more rapidly (418 cases reported in Liverpool in 1987 as compared with 288 cases in 1986). This change may be due in part to the increasing awareness in the community due to recent media campaigns.

Recent work (Grey, 1987; Weller, 1987) has drawn attention to some of the factors that influence the aggressive personality. They include the quality of the home environment both in socio-economic and psychological terms (particularly if there is a violent tendency in the parents), the exposure of young minds to violence in the media and some organic factors such as epilepsy. Alcohol is a recognized factor in the aetiology of many acts of violence in adulthood (Driscoll et al., 1988). In this group however, alcohol was not recognized as a problem, although routine screening was not employed.

During the period of this study, cases of assault did not exert an appreciable load on the A\&E Department in terms of time and resources unless there was suspicion of abuse by an adult. This sub-group took up considerable medical and nursing time and affected the morale of the staff. In the future there should be a study of the long term morbidity of these incidents. In physical terms the likelihood of chronic disability is low. Post-traumatic stress disorder has been described in some detail after major disasters (Raphael \& Middleton, 1988), but long term psychological effects may occur after assault.

This study has emphasized the increased likelihood of physical and sexual abuse in children of pre-secondary school age who are brought to A\&E after an alleged assault. Many A\&E departments have developed close links with social services and counselling agencies and a multidisciplinary approach might be beneficial after selected cases of assault.

\section{REFERENCES}

Driscoll P., Smith J. \& Burdett-Smith P. (1988) A Study of assault victims attending three London accident and emergency departments. British Journal of Accident and Emergency Medicine 3, 5-9.

Gray O. P. (1987) Violence and Children. Archives of Disease in Childhood 62, 428-430.

Raphael B. \& Middleton W. (1988) After the horror. British Medical Journal 296, 1142-1143.

Weller M. P. I. (1987) Aspects of violence Lancet ii, 615-617. 